\title{
Validation of Nonlinear Bipolar Transistor Model by Small-Signal Measurements
}

\author{
Vidkjær, Jens; Porra, V.; Zhu, J.; Huttunen, T
}

Published in:

Proceedings of the 22nd European Microwave Conference

Link to article, DOI:

10.1109/EUMA.1992.335870

Publication date:

1992

Document Version

Publisher's PDF, also known as Version of record

Link back to DTU Orbit

Citation (APA):

Vidkjær, J., Porra, V., Zhu, J., \& Huttunen, T. (1992). Validation of Nonlinear Bipolar Transistor Model by SmallSignal Measurements. In Proceedings of the 22nd European Microwave Conference (Vol. Volume 2, pp. 12171222). IEEE. https://doi.org/10.1109/EUMA.1992.335870

\section{General rights}

Copyright and moral rights for the publications made accessible in the public portal are retained by the authors and/or other copyright owners and it is a condition of accessing publications that users recognise and abide by the legal requirements associated with these rights.

- Users may download and print one copy of any publication from the public portal for the purpose of private study or research.

- You may not further distribute the material or use it for any profit-making activity or commercial gain

- You may freely distribute the URL identifying the publication in the public portal 


\title{
VALIDATION OF NONLINEAR BIPOLAR TRANSISTOR MODEL BY SMALL-SIGNAL MEASUREMENTS
}

\author{
J. Vidkjær *, V. Porra**, J. Zhu**, T. Huttunen**
}

\begin{abstract}
A new method for the validity analysis of nonlinear transistor models is presented based on DCand small-signal S-parameter measurements and realistic consideration of the measurement and de-embedding errors and singularities of the small-signal equivalent circuit. As an example, some analysis results for an extended Gummel Poon model are presented in the case of a UHF bipolar power transistor.
\end{abstract}

\section{INTRODUCTION}

New systems concepts such as coding and modulation schemes together with the need of circuit integration of the modern telecommunication systems require more accurate nonlinear circuit modelling for the transistors in the power stages. The bipolar transistor models available in commercial simulation programs may not be adequate to predict the system behaviour. For improving and modifying the models, new model validation tools are needed. A good model should follow all the measured data within the measurement tolerances, and it should have minimum complexity and well defined parameters.

Recently, an efficient method has been presented for evaluating the small-signal parameter uncertainties caused by scattering parameter measurement errors and model singularities $/ 1 /$. This information can be efficiently used for nonlinear model validation as well.

In the present study, this method has been used to test the validity of the extended Gummel-Poon model used in many simulation programs (as SPICE or APLAC /5/). The new aspect in this modelling scheme is the realistic consideration of the measurement and paramerter estimation errors and the possibility to minimize the model complexity according to the quality of the measured data. Furthermore, the tolerance information may be utilized to evaluate the reliability limits of the final circuit design. It may also give an early warning of the need of more detailed and accurate characterization measurements and modelling.

\section{TOLERANCE ANALYSIS BY SINGULAR VALUE DECOMPOSITION /1/}

The basic concept of the small signal model extraction is to utilize network analyzer uncertainty data as a measure for the quality of the result. If a proposed model gives responses which differ more from the measured data than indicated by the uncertainties, the model can not provide reliable parameter values and a better one should be found. If, on the other hand, the model is acceptable, uncertainty data are further used to estimate the expected parameter deviations and their correlations. From these figures, it is possible to identify components in the model which are

* Electromagnetics Inst., Technical Univ. of Denmark, DK-2800 Lyngby, Denmark

** Electronic Circuit Design Lab., Helsinki Univ. of Technology, SF-02150 Espoo, Finland 
superfluous and should be discarded, because their inaccuracies may transfer to parameters which otherwise could be more precisely found.

The basic theory of the method is described in $/ 2 /$. Briefly, the technique is to fit the model function $\boldsymbol{M}(\boldsymbol{p})$ of the parameter array $\boldsymbol{p}$ of $n$ parameters $p_{i}, i=1 \ldots n$, using the objective function

$$
E=\frac{1}{m} \sum_{i=1}^{m}\left(M(p)_{i}-S_{i}\right)^{2} / u_{i}^{2}
$$

Here $m$ is the number of measured data components $S_{i}, \boldsymbol{M}(\boldsymbol{p})_{i}$ and $u_{i}$ represent the measured data (here S-parameters) value, the model response and the corresponding $99.9 \%$ measurement uncertainty tolerance, respectively. In the ideal case with normally distributed and uncorrelated measurement errors, the optimal set of parameters should bring the error down to about $E_{\min }=0.3$. Larger error indicates either poor model topology or problems in measurements. Applying the singular value decomposition techniques $/ 2 /$ to the sensitivity matrix of the model, $\boldsymbol{A}=\left\{a_{i j}\right\}=\left\{p_{j}\left(\partial \boldsymbol{M}(\boldsymbol{p})_{i} / \partial p_{j}\right) /\left(u_{i} \sqrt{m}\right)\right\} \quad$ yields

$$
A=U W V^{t}, \quad W=\operatorname{diag}\left(W_{1}, W_{2},, W_{n}\right)
$$

$\boldsymbol{U}$ is a $m x n$ and $\boldsymbol{V}$ a $n x n$ orthonormal matrix. In the $n$-dimensional parameter space the error surface $E=$ const. is an ellipsoid with principal axes along the column vectors of the orthonormal matrix $V$. The lengths of the axes are proportional to $1 / W_{i}, i=1 \ldots n$. Very low or zero singular values $W_{i}$ indicate, that the model contains insignificant components. The problems of small singular values may be quantified through the covariance matrix for the relative parameter variations. Its elements are given by

$$
C o v_{i j}=\frac{E_{\min }}{m-n} \sum_{k=1}^{n} V_{j k} V_{i k} / W_{k}^{2}
$$

The equation shows that small singular values contribute large deviations to the parameters upon which they are projected through the rows of $V$. Table 4 below shows an example of the process. The relative deviations are the square roots of the diagonal elements $\operatorname{Cov}_{i i}$. The relative intersections (of the error ellipsoid) show how large the relative deviation of a parameter would be if all other parameters would have no deviations. The last column gives the singular values tabulated together with the parameter to which they contribute the largest deviation.

\section{GUMMEL-POON MODEL WITH STRAY ELEMENTS}

Fig. 1 shows the Gummel-Poon model $/ 3 /$ and a 'template' small-signal equivalent circuit having maximal complexity including stray inductors and capacitors. Most of the intrinsic nonlinear parameters were first extracted from DC- and low frequency measurement data. The relevant (SPICE) parameters with statements on extraction acccuracy (good/fair/poor) are shown in Table 1. The forward transit time as well as the encapsulation parameters were left to be adjusted on the basis of the small signal equivalent circuit. 


\begin{tabular}{|l|l|l|l|l|l|l|l|l||}
\hline \hline $\mathrm{BF}$ & $\mathrm{IS} / \mathrm{fA}$ & $\mathrm{NF}$ & $\mathrm{VAF} / \mathrm{V}$ & $\mathrm{IKF} / \mathrm{mA}$ & $\mathrm{ISE} / \mathrm{fA}$ & $\mathrm{NE}$ & $\mathrm{RB} / \Omega$ & $\mathrm{RE} / \mathbf{\Omega}$ \\
\hline \hline 102 & 12.9 & 1.03 & 77 & 147 & 387 & 2.03 & 0.94 & 1.27 \\
\hline good & fair & fair & fair & poor & poor & poor & poor & poor \\
\hline $\mathrm{RC} / \Omega$ & $\mathrm{CJE} / \mathrm{pF}$ & $\mathrm{VJE} / \mathrm{V}$ & $\mathrm{ME}$ & $\mathrm{CJC} / \mathrm{V}$ & $\mathrm{VJC} / \mathrm{V}$ & $\mathrm{MC}$ & $\mathrm{XTB}$ & XTI \\
\hline \hline 1.3 & 8.79 & 0.723 & .334 & 7.56 & 0.592 & 0.332 & 1.818 & 3.0 \\
\hline poor & fair & fair & fair & fair & fair & fair & poor & poor \\
\hline
\end{tabular}

Table 1. Relevant Gummel-Poon model parameters extracted from static and low frequency measurements
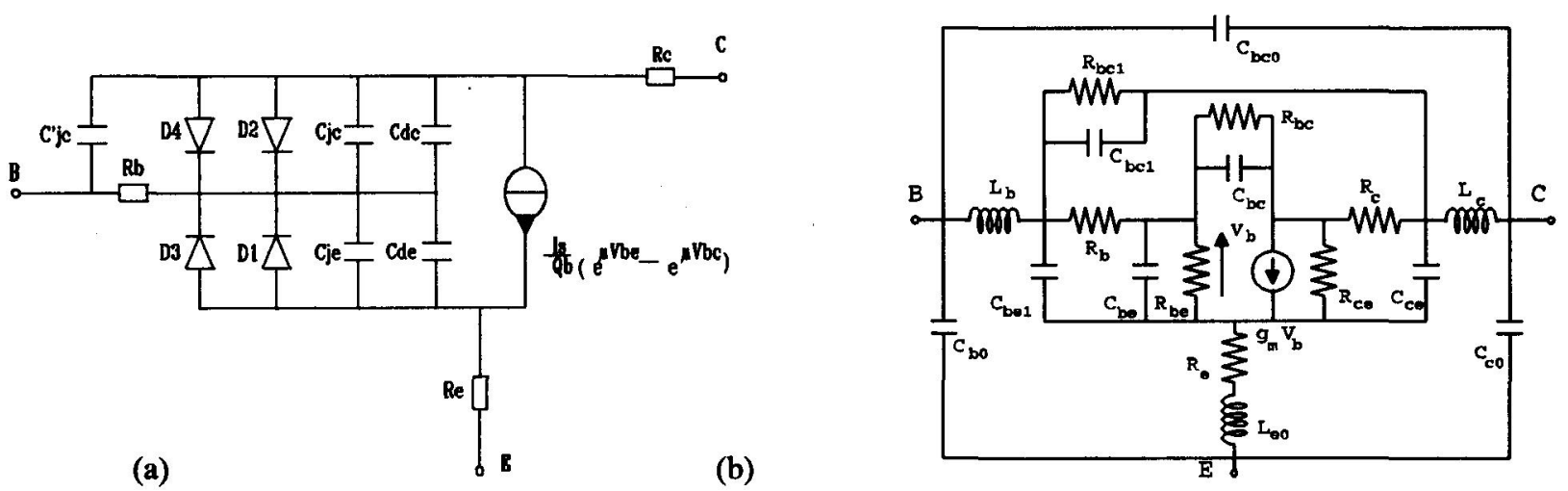

Fig. 1 Gummel-Poon model (a) and the corresponding small signal equivalent circuit including encapsulation parameters (b).

\section{SMALL SIGNAL PARAMETER EXTRACTION}

The small-signal scattering parameters were measured by an automatic network analyzer (HP8753C) using a transistor fixture (HP11608A). The bias conditions of these measurements are shown in Table 2. The measurement uncertainties were estimated on the basis of the instrument data.

\begin{tabular}{|c|c|c|c|c|c|}
\hline & saturated & $\begin{array}{l}\text { forward } \\
\text { active }\end{array}$ & $\begin{array}{l}\text { near cut- } \\
\text { off }\end{array}$ & $\begin{array}{l}\text { forward } \\
\text { active }\end{array}$ & $\begin{array}{l}\text { forward } \\
\text { active }\end{array}$ \\
\hline$T_{a m b}$ & $20^{\circ} \mathrm{C}$ & $20^{\circ} \mathrm{C}$ & $20^{\circ} \mathrm{C}$ & $-30^{\circ} \mathrm{C}$ & $+80^{\circ} \mathrm{C}$ \\
\hline $\mathrm{I}_{\mathrm{C}}$ & $99.67 \mathrm{~mA}$ & $29.74 \mathrm{~mA}$ & $0.52 \mathrm{~mA}$ & $29.5 \mathrm{~mA}$ & $29.89 \mathrm{~mA}$ \\
\hline$V_{C E}$ & $0.159 \mathrm{~V}$ & $3.01 \mathrm{~V}$ & $6.0 \mathrm{~V}$ & $3.01 \mathrm{~V}$ & $3.01 \mathrm{~V}$ \\
\hline $\mathrm{V}_{\mathrm{BE}}$ & $1.8 \mathrm{~V}$ & $0.804 \mathrm{~V}$ & $0.658 \mathrm{~V}$ & $0.89 \mathrm{~V}$ & $0.72 \mathrm{~V}$ \\
\hline$\beta_{D C}$ & 6.83 & 101.8 & 98.8 & 66.4 & 133.1 \\
\hline
\end{tabular}

Table 2.Summary of bias conditions

The small signal equivalent circuits were extracted using linear optimization program LCP2 written by Gaunholt $/ 4 /$. The extraction results are given in Table 3. A typical plot of the model fit for the active operating point is shown in Fig 2. Typical parameter tolerances for the active operating point, based on singularity analysis are shown in Table 4 . 


\begin{tabular}{|c|c|c|c|c|c|}
\hline MRF557 & & $20^{\circ} \mathrm{C}$ & & $-30^{\circ} \mathrm{C}$ & $+80^{\circ} \mathrm{C}$ \\
\hline Parameter & $\begin{array}{l}\text { saturation } \\
100 \mathrm{~mA}, 0.2 \mathrm{~V}\end{array}$ & $\begin{array}{l}\text { fwd active } \\
30 \mathrm{~mA}, 3 \mathrm{~V}\end{array}$ & $\begin{array}{c}\text { cut-off } \\
0.5 \mathrm{~mA}, 6 \mathrm{~V}\end{array}$ & $\begin{array}{c}\text { active } \\
30 \mathrm{~mA}, 3 \mathrm{~V}\end{array}$ & $\begin{array}{c}\text { active } \\
30 \mathrm{~mA}, 3 \mathrm{~V}\end{array}$ \\
\hline $\begin{array}{l}\text { Encapsulation } \\
L_{b} / \mathrm{nH} \\
L_{c} / \mathrm{nH} \\
L_{e o} / \mathrm{nH} \\
C_{b o} / \mathrm{fF} \\
C_{c o} / \mathrm{fF} \\
C_{b c o} / \mathrm{fF} \\
\end{array}$ & $\begin{array}{l}1.056 \\
0.382 \\
0.839 \\
29.26 \\
293.3 \\
23.69\end{array}$ & $\begin{array}{l}1.034 \\
0.354 \\
0.825 \\
27.21 \\
337.1 \\
58.46\end{array}$ & $\begin{array}{l}1.082 \\
0.357 \\
0.834 \\
14.77 \\
332.3 \\
42.74\end{array}$ & $\begin{array}{l}1.185 \\
0.514 \\
0.843 \\
98.42 \\
317.9 \\
29.59\end{array}$ & $\begin{array}{l}0.954 \\
0.341 \\
0.812 \\
10.85 \\
335.2 \\
27.82\end{array}$ \\
\hline $\begin{array}{l}\text { Intr.transistor } \\
R_{b b} / \Omega \\
C_{b e l} / \mathrm{pF} \\
C_{b e} / \mathrm{pF} \\
R_{b e} / \Omega \\
g_{m} / \mathrm{S} \\
C_{c e} / \mathrm{pF} \\
R_{c e} / \mathrm{k} \Omega \\
C_{b c l} / \mathrm{pF} \\
R_{b c l} / \mathrm{k} \Omega \\
C_{b c} / \mathrm{pF} \\
R_{b c} / \Omega \\
\end{array}$ & $\begin{array}{l}1.236 \\
- \\
990.8 \\
- \\
1.846 \\
- \\
- \\
29.26 \\
- \\
- \\
1.256\end{array}$ & $\begin{array}{l}1.846 \\
9.818 \\
38.78 \\
132.9 \\
0.784 \\
1.074 \\
4.337 \\
4.011 \\
- \\
- \\
-\end{array}$ & $\begin{array}{l}2.731 \\
12.68 \\
17.84 \\
5.246 \\
0.0195 \\
1.129 \\
- \\
2.943 \\
- \\
- \\
-\end{array}$ & $\begin{array}{l}1.626 \\
10.89 \\
41.86 \\
78.48 \\
0.906 \\
1.229 \\
- \\
3.977 \\
73.69 \\
- \\
-\end{array}$ & $\begin{array}{l}2.268 \\
9.113 \\
37.92 \\
188.13 \\
0.704 \\
0.730 \\
2.558 \\
3.366 \\
- \\
0.704 \\
-\end{array}$ \\
\hline$E_{\min }$ & 0.713 & 1.033 & 0.706 & 1.105 & 0.898 \\
\hline
\end{tabular}

Table 3: Summary of the extracted small signal parameter values. Missing values (including resistors $R_{c}$ and $R_{e}$ ) indicate parameters which have been discarded because of singularities and poor influence in $E_{\min }$.

\begin{tabular}{||l|l|l|l|l||}
\hline Param. & Value & $\begin{array}{l}\text { Rel.inter- } \\
\text { section \% }\end{array}$ & $\begin{array}{l}\text { Rel. de- } \\
\text { viation \% }\end{array}$ & $\begin{array}{l}\text { Singular } \\
\text { value }\end{array}$ \\
\hline \hline$L_{b} / n A$ & 1.034 & 1.17 & 1.93 & 6.954 \\
$C_{b o} / f F$ & 27.81 & 23.47 & 44.24 & 0.175 \\
$C_{b c o} / f F$ & 58.46 & 15.24 & 23.79 & 0.345 \\
$C_{b e l} / p F$ & 9.818 & 3.41 & 17.00 & 0.473 \\
$R_{b b} / \Omega$ & 1.846 & 4.76 & 8.16 & 1.646 \\
$C_{b e} / p F$ & 38.78 & 0.99 & 4.86 & 5.949 \\
$R_{b c} \Omega$ & 132.9 & 2.21 & 2.48 & 3.149 \\
$C_{b c l} / p F$ & 4.011 & 0.46 & 0.61 & 18.671 \\
$C_{c e} / p F$ & 1.074 & 5.44 & 6.90 & 1.126 \\
$g_{m} / m S$ & 784.4 & 0.57 & 0.88 & 13.726 \\
$R_{c e} / k \Omega$ & 4.337 & 58.23 & 64.63 & 0.126 \\
$L_{c} / p H$ & 353.8 & 2.01 & 3.60 & 3.767 \\
$L_{e d} / p H$ & 825.4 & 0.55 & 1.17 & 14.707 \\
$C_{c o} / \mathrm{fF}$ & 337.2 & 2.78 & 5.17 & 1.961 \\
\hline
\end{tabular}

Table 4. Singularity analysis results, forward active, $20^{\circ} \mathrm{C}$ 

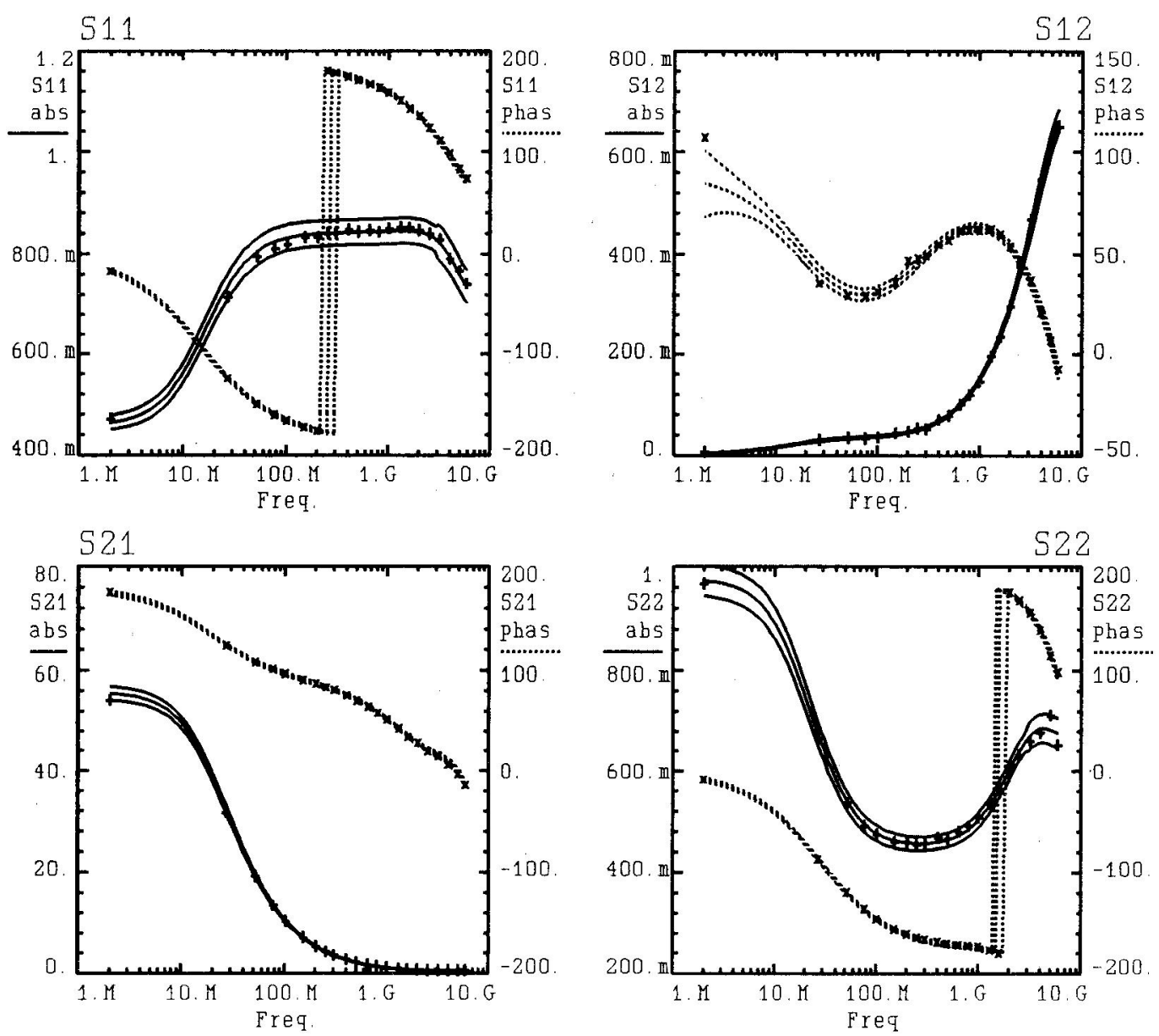

Fig.2. Small signal model fit at $I_{C}=30 \mathrm{~mA}, V_{C E}=3 \mathrm{~V}, 20^{\circ} \mathrm{C}$. Measured data: Magnitude (+), phase (x). The curves show response of the fitted model surrounded by the upper and lower $99.9 \%$ uncertainty bounds for the network analyzer alone (Fixture not included in uncertainties but of course in calibrations.

\section{ADJUSTMENT OF SOME GUMMEL-POON MODEL PARAMETERS}

The most important contribution from the small-signal model to large-signal modelling is the correct topology of both the encapsulation parasitics and the details of the base region. The major encapsulation parameters in Table 3 show relatively good consistency. The temperature dependence of the series inductances is caused by calibration offset, while the low and high temperature measurements were made using room temperature calibration.

One of the modelling difficulties of bipolar transistors is the division of the base-collector capacitance to the active and base-collector overlay parts. In this case, the parameter values of Table 3 show clearly, that the overlay capacitance dominates the feedback from collector to base, and the active junction capacitance cannot be distinguished at all.

The small signal analysis may considerably improve the accuracy of the important corner point current parameter $I_{k}$ (IKF in Table 1). A rough approximation of the G-P model equations for the collector current in the forward active region is 


$$
I_{C}=\frac{I_{s} e^{V_{E B} / V_{t}}}{1+I_{C} / I_{k}} ; \quad V_{t}=k T / q
$$

Ideally, the transconductance would be $g_{m}=\partial I_{C} / \partial V_{B E}=g_{m i}=I_{C} / V_{t}$. Differentiating the above equation and using the values of $g_{m i} / g_{m}$ from Table 3 one gets $I_{k}=120 \mathrm{~mA}$ with a better precision than from the Gummel plot, Table 1.

One of the problematic parameters in a G-P-model is the base diffusion transit time $\tau_{\mathrm{f}}$. Because the diffusion capacitance should be proportional to the current, we may estimate it to be $C_{d}=C_{b e}(30 \mathrm{~mA})-C_{b e}(0.5 \mathrm{~mA})=20.94 \mathrm{pF}$. This gives $\tau_{F}=26.7 \mathrm{ps}$ which corresponds to the 'intrinsic' unity gain cutoff frequency of $\mathrm{f}_{\mathrm{T}}=6 \mathrm{GHz}$. The value obtained in this case from the slope of the current amplification factor beta derived from $S$-parameters would be $f_{T}=2.6 \mathrm{GHz}$ which consists mainly from the excess delay $R_{b b} C_{b e}$ caused by the base resistance.

The static temperature behaviour is only taken into account by the two parameters XTB and XTI in the G-P-model. The dynamic variation of the transistor behaviour is much more complicated and can be seen from the small signal parameters in Table 3. This information can be used to improve the temperature behaviour of the Gummel-Poon model. Some idea of the consistency of the small signal and nonlinear models may be obtained by comparing the current amplification $\beta$ calculated from table 3 ( $\beta=\mathrm{g}_{\mathrm{m}} \mathbf{R}_{\mathrm{be})}$ and Table 2. The temperature variation of the dynamic values of $\beta$ follows $5 \%$ that obtained from static Gummel plots.

One further problem in the G-P-model is the division of the base resistance $R_{b b}$ (RB in Table 1) in two parts, one of which is constant and the other depends on operating point. The constant part can be found from the small signal equivalent circuit in saturation $(1.24 \Omega)$

\section{CONCLUSION}

A new method for error tolerance analysis of small signal models $/ 1 /$ has been applied to the nonlinear modelling of a bipolar power transistor. The information available on the error tolerances makes it possible to select the right model complexity corresponding to the measurement accuracy. In nonlinear model validation, it also indicates the need of extended characterization measurements, if the uncertainty of the model behaviour turns out to be too large for the design problem to be solved.

\section{REFERENCES}

1 Jens Vidkjær, Accuracy Bounds in Small-Signal Model Identification, Proc. 10th European Conf. Circuit Theory and Design, Sep.2-6., pp. 782-791, 1991

2 C.L.Lawson, R.J.Hanson, Solving Least Squares Problems, Prentice-Hall 1974

3 P. Antognetti, G. Massobrio (ed.), Semiconductor Device Modeling with SPICE, McGraw-Hill 1988

4 H. Gaunholt, LCP2- A general purpose circuit optimization program, Proc. SPACECAD'79, Bologna, Italy pp. 99-109, ESA-SP-146, Nov. 1979

5 M. Valtonen et al., APLAC An Object-Oriented Analog Circuit Simulator and Design Tool, 6.0 Reference Manual, Helsinki University of Technology, Espoo Finland Oct. 1991 Circuit Theory Laboratory, Espoo, Finland, Oct. 1991 